\title{
Corrigendum: Common variants in ACYP2 influence susceptibility to cisplatin-induced hearing loss
}

Heng Xu, Giles W Robinson, Jie Huang, Joshua Yew-Suang Lim, Hui Zhang, Johnnie K Bass, Alberto Broniscer, Murali Chintagumpala, Ute Bartels, Sri Gururangan, Tim Hassall, Michael Fisher, Richard Cohn, Tetsuji Yamashita, Tal Teitz, Jian Zuo, Arzu Onar-Thomas, Amar Gajjar, Clinton F Stewart \& Jun J Yang

Nat. Genet. 47, 263-266 (2015); published online 9 February 2015; corrected after print 13 March 2015

In the version of this article initially published, the authors neglected to acknowledge that the work was also supported by US National Institutes of Health grant R01 CA154619. The error has been corrected in the HTML and PDF versions of the article. 